\title{
Reforming governmental geosciences in central Europe - A case study from Hungary
}

\begin{abstract}
The establishment of democratic governments in Eastern Europe has brought many problems to the forefront and has created arduous tasks, namely that the laws, the regulations, and the Governments' regulatory bodies have to be restructured if they are to survive in market economies. Scientific institutions, such as those in Hungary, also are affected by this transformation. This article, a case study of the governmental geosciences in Hungary, summarizes the trials and tribulations of and the educational process involved in transforming institutions from central planning and decision-making roles, as well as from positions of authority, to the public-service role. The lessons learned are that new institutions always are easier to create than existing ones are to restructure, that concerns about organizational structure will overwhelm interests in developing an agency's mission, and that the public-service role will take a long time to develop. The story presented here is an unfinished one for the reasons just mentioned, but it may serve to guide those who have embarked on the same task elsewhere in central and Eastern Europe and perhaps in countries that have emerged from the ashes of the former Soviet Union.
\end{abstract}

$N_{o \text { word is dreaded more in geoscience communities than the word }}$ "reform," especially institutional reform. Yet changes are needed to revitalize institutions more frequently than is measurable on a geologic time scale, and examples have abounded from Germany, the United Kingdom, Sweden, Canada, and elsewhere in just the past decade. In these geological surveys, science has kept abreast with developments in geological concepts and practices, or, rather, their scientists have been in the forefront in developing them, in no small part owing to their ability to adjust to changing times and owing to the challenge set by profit-oriented companies of a market economy.

\section{Historical background}

Hungary is a country $93,000^{2} \mathrm{~km}$ in extent (the size of the State of Indiana in the USA) and has a population of 10 million. This small country has a limited domestic "geomarket" and is easy to isolate because of its language, which is not related to any major language of the technical and scientific literature (for example. English, German, and French). Prior to the Communist takeover in 1948, Hungary had flourishing, appropriately sized mining enterprises, including a joint venture American-Hungarian oil company, a small geological survey providing information to all citizens, and a clear-cut separation of the responsibilities of the private sector from those of the Government, which served the needs of the public at large.

The Communist regime that came to power in 1948 confiscated and nationalized private properties. Where resistance was shown by the managers of companies, show trials and imprisonment were used to coerce the results. The functions and staff of small government agencies were expanded to provide control over the assets, to set quite unreasonable production targets, and to regulate adherence to these aims. The latter process culminated in the early 1960s when expansion was accelerated in order to meet industrial production targets set by the goals of a so-called "self sufficiency" that was coupled to the adoption of a standardized Soviet model. This model encompassed legislation, regulations, organizations, and the role of the Academy of Sciences. This reorganization took place throughout

$$
\begin{gathered}
\text { "No word is dreaded more } \\
\text { in geoscience communities than the } \\
\text { word 'reform,' especially } \\
\text { institutional reform." }
\end{gathered}
$$

Eastern and central Europe at about the same time; hence, institutions became nearly identical in their scope of activities, methods of operation, and organizational structure.

For the employees of the State-owned companies and the Government's administration alike, the ideology-driven expectations and demands for the next 40 years resulted in, for instance:

- Education that forced the employees to imitate and show an acceptance for the Soviet model and its application in the workplace

- Employment at wages that were kept artificially so low that, by the early 1980s, income from year-end bonuses paid on the basis of inflated performance figures and income from "economic work associations," which completed tasks after hours, exceeded base pay severalfold and thus removed the incentive for work at the workplace

- A permanent housing shortage that hampered the mobility of the population, including the professional people, and made it difficult to switch jobs among industry. Government, and higher education institutions. even though each sector was controlled by the State

- An attitude oriented to minerals production that was without cost to benefit analysis and that neglected serious social, environmental, and economic consequences

- Respect and recognition that were more easily gained for professionals through Communist Party channels, advancement also being subject to the same

- Insulation from Western scientific progress for nearly 40 years that was compensated for by "home-grown" and Soviet-directed sci- 
ence (for example, the reluctance by the Soviets to accept the concept of plate tectonics)

- Production of great quantities of reports that were tied to the bonus system but had no peer review and no readership

Such circumstances and isolation produced endemic geoscience overall in Hungary. Exceptions existed on an individual basis, as a few scientists found ways to work with Western colleagues, but these exceptions were seldom on an institutional scale.

\section{The current situation}

What are the characteristics of such an institutional system that, prior to World War II, held its own professionally in the region?

The first characteristic is its size. The geoscience institutes, as measured by their budgets and numbers of employees, grew manyfold in the late 1950s to early 1960s during the ideologically driven period of industrial expansion. This ideology aimed to sever dependence on anything from the West. Smelters and steel mills were built without local supplies of iron ore. Coal mining was expanded to megascale proportions in order to produce electricity for resourceless industries or for those that attempted to duplicate products no longer available, or wanted, from the West. To meet the demand, geologists, geophysicists, and mining engineers were graduated in droves. As a result, nearly 10,000 people have "geodegrees" in Hungary. Not all the graduates went to work in mines and associated plants. A commensurate number of graduates were employed in science institutions that conducted surveys for raw materials, planned industrial projects according to the State's 5-year plans, and administered and regulated everything - all without regard to profitability. The number and variety of research institutes exploded, driven by the false ideology, imposed by the Communist Party, that "Socialist" governmentfunded science would subdue its capitalist equivalents.

In this manner, the Hungarian Geological Institute's employment roster grew from 58 in 1947 to close to 1,000 by the 1960 s, and the roster of the Eötvös Lóránd Geophysical Institute (once a university institute set up by the famous geophysicist, L. Eötvös) grew from about 40 after World War II to more than 1,500 during the same time period. Today, after 2 years of staff reductions, they still stand at 380 and 500 , respectively. The staffs of the geological surveys of comparably sized countries, such as Austria and Portugal, today are about 140, including the geophysicists and geochemists, the latter of whom in Hungary are housed in a separate research institute belonging to the Academy of Sciences.

Similar growth was observed at the Academy of Sciences, which was remodeled in the early 1960s to fit the Soviet version; 37 research institutes were created, some of which employed as many as 3,000 people. Each found a niche in the spectrum of scientific research.

The second characteristic, and more critical problem, was the artificial apportioning of geosciences into separate institutions. Several factors played a part in this: the Communist power structure and its system of rewards (kingdoms and kingpins), the demand for tasks and products of narrow scopes, ample budgets without accountability, and the need to fit all of this into a similarly designed Communist Countries Economic Association (COMECON) system that had committees for every conceivable subject but had few accomplishments.

In no time at all, geologists, geophysicists, and a woefully few geochemists all worked in separate, relatively isolated institutions. The situation was compounded further not only by the disciplines of geodynamics, geodesy, and seismology each going it alone but also by the fact that the university departments were compartmentalized along the same lines. In this manner, the academic institutions did produce students having high-caliber basic, albeit narrow, education in the disciplines of geoscience, but the graduates' subsequent assignments never allowed them to broaden their knowledge by working in interdisciplinary teams. The structure of the institutions that hired them, as well as the unwritten principle of no one elevating himself or herself above the party's "nomenklatura" by being only a good scientist, ensured that they would remain subservient to the party's interests. Furthermore, the monopolistic nature of the Staterun mining companies resulted in no real demand for an interdisciplinary approach to geological questions.

Thus, Hungarian geophysicists are well educated in physics and mathematics, and geologists are well educated in stratigraphy, mineralogy, and paleontology. However, for lack of interdisciplinary work or exchanges with the West, their opportunities were curtailed for becoming familiar with other, or related, disciplines or for partaking in the testing of fast-advancing geological concepts.

Because of a lack of hands-on experience with the developments in plate tectonics, mathematical geology, basin analysis, and geohazards evaluation, certain geoscience disciplines never developed fully. Sedimentology, sedimentary and carbonate petrography, diagenesis, facies analysis, paleoenvironmental reconstruction, environmental geology, marine geology, and tectonics were either cursorily touched upon or were not taught at all. This situation put its mark on the institutes' work as well. As science was directed from above, many of the basic subjects suffered even malpractice, which was evidenced by the emphasis on formation stratigraphy rather than on combined litho-, bio-, and chronostratigraphy. The same can be said for the interpretation of geophysical data, interpretation that was practiced independently of, or inadequately matched to, geology.

$$
\begin{gathered}
\text { “To many, the leap from today's } \\
\text { Hungarian geology situation to } \\
\text { something resembling any } \\
\text { Western European geological survey } \\
\text { seems too radical, too inconvenient, } \\
\text { too soon." }
\end{gathered}
$$

The third characteristic and problem in Hungarian reform is the "ingrained habit" factor. The 40 years of familiarity with a certain organizational-operative system and no in-depth experience with any other together have created a situation whereby all attempts at reform (that is, designing a new concept of mission-organization-operation) somehow revert to the former state. In part, this is caused by inertia. To many, the leap from today's Hungarian geology situation to something resembling any Western European geological survey seems too radical, too inconvenient, too soon. The need to cut employment certainly is threatening on a personal basis. What also plays a role in this, however, is that the average age of the geoscientists has reached the 50s (most were hired in the 1950s and 1960s). and because of this, their willingness to change, understandably, is not as great as for those who are about to climb the career ladder. Acceptance also is countermanded by fear of the unknown. Almost all the geoscientists were weaned on and practiced minerals-related work; in the future, this field will be the responsibility of the private companies, which will necessitate learning new applications of the geosciences.

The fourth characteristic to contend with is the social problem. The large-scale institutional employment required control. and a subservient supervisory class was cultivated from among party favor- 
ites to administer the institutions. These people were oriented to gaining position and power, rather than to producing results for the society at large. In carrying out the directives of 5-year plans (whose results often were falsified), they were rewarded by a few opportunities and privileges, such as travel to foreign countries and access to foreign currencies. The supervisors occasionally shared such privileges with their subordinates, which expanded the size of the class over time. The subordinates, nonetheless, remained underpaid, and as their career advancement remained restricted, the progress of their scientific education was limited to the domestic arena.

Since 1989, most of these privileges, at all levels, have eroded or become commonplace. Retirement or unemployment has become imminent, and retrainability remains low mostly on account of age and overspecialization. This social stratum, which never had to generate its own financial resources to survive, is still vocal because it used to be important and used to be appreciated. As it sees the private sector taking over the Government's functions now, this stratum is very concerned about the future. This is true also of those employed in the earth sciences and by the mining companies, mostly because investment in the minerals sector is expected to be foreign or will try to meet Western standards, and the fear exists that competing with these may be individually beyond reach.

The fifth characteristic, and most contentious problem, is related to the future role of governmental science. Because everything was planned, authorized, budgeted, directed, executed, and spent by the State under the old system, the lines between the activities of Government and industry had become completely blurred. One served the other and the other way around - a habit not yet quite broken. Thus, governmental science institutes developed a profile that included industrial research, development, manufacturing, marketing, and service. Their markets were the COMECON countries, principally the Soviet Union, where technology, especially "high technology" (with or without quality control), was welcome due to the embargo on technology by the Western countries. Upon the fall of the Iron Curtain, this market has collapsed and leaves in its wake overstuffed organizations, unused facilities, aged equipment, and a large, unaffordable social-benefit network of recreational property and services. With governmental cutting of costs underway in Hungary, most of this infrastructure is now unaffordable; therefore, the Government is driven to privatize the sector, including research institutions, that is not needed in government service. Much resistance to privatization is felt, though, because everyone knows that none of the skills, equipment, or facilities can compete economically with the genuinely private sector that has gotten, or will get, used to watching the bottom line. The current Government cannot afford more than a few slimmed-down institutes that are absolutely necessary to fill the public needs and to support policy making. Still, attempts are made daily to justify keeping afloat the unnecessary and the unsustainable.

\section{Ways and means of restructuring}

Given these preconditions, how can Hungarian governmental geoscience be restructured to make it survive?

One may approach reorganization as if faced with an ineffective corporation. Evaluate the assets and liabilities, define a mission (market), divest noncore activities, pare down and reorganize elements into functional lines of responsibility, assign new management where needed, develop a strategy, and request a budget that is justified to meet the targets of this strategy.

This is easier said than done. Not uncharacteristically, most people worldwide are more interested in organizational structure and who their superiors will be - that is, where they will fit in-than are concerned about missions, goals, and tasks. Hence, agreeing on the scope and schedule of activities is viewed with muted interest. Still, these are the critical elements because, without them, the structure and the personnel filling the structure will not be cohesive and will not be productive.

The first step taken early in 1991 was, therefore, to define what a new geological survey ("service" in Hungarian because "survey" means cadastral measurements) should be doing in the future. A specific minerals-related role was sought for the geoscientists as a result of the fact that a new concession-based mining (mineral and petroleum exploration and production) law was being prepared at that time (it is now in Parliament). This proposed law also aimed to set up a regulatory agency to manage the concessions, as well as to manage other aspects of the mining sector. It seemed reasonable that mineral and energy resource assessment and concession-related data management activities would be an appropriate objective for the new survey (in some form, already a task of the Hungarian Geological Institute). The subject area was familiar, and thus pacifying, to the geologists and geophysicists, but it continues to require major readjustment in their reasoning, whereby the emphasis is placed on economic principles. Other missions were defined: the evaluation of the geological aspects of water resources and the natural environment, digital mapping, the evaluation of geohazards and related engineering geology, agrogeology to help manage agricultural resources, and the combining of environmental sciences and geology in order to assist in cleaning up pollution and in developing guidelines to protect the environment.

". . most people worldwide
are more interested in organizational
structure and who their superiors
will be-that is, where they
will fit in-than are concerned
about missions, goals, and tasks."

These other missions are new. Their practice will require a rather long preparation, acceptance, and implementation period given the present institutional capabilities and, therefore, will become an integral part of the mission of the geological survey only if a younger generation is hired to plan and carry these activities through. This is a sad commentary because of the urgent need for answers countrywide at all levels by central and municipal governments, folding and fledgling industries, and even by individual citizens. A few decades ago, geologists were on the scene who could foresee and investigate problems of national magnitude, many of whom carried their work through in the 1950s in face of hostility and complacency, because they were much better generalists. This is the key: the new generation must be, for the larger part, familiar with a much wider range of current geological concepts and practices.

Concepts will be put into practice only if all the disciplines are working together. This, in reality, means that separate scientific evaluations by geologists and geophysicists (still not involving adequate geochemical analyses) cannot be afforded, in spite of the desire to hold onto tradition (that is, habit), organizational independence (familiar surroundings), and scientific independence (tunnel vision). The contest is essentially about (1) bringing geologists and geophysicists under one roof, (2) adding engineering geology (the reduced staff of the former Central Institute of Mining Research and Devel- 
opment, KBFI), and (3) expanding the scientific knowledge base by adding hydrologists, biologists, chemists, statisticians, and other needed experts.

Bringing two independent organizations under one roof is viewed as a positive step, but still a choice must be made regarding the host. Of the two institutes slated for amalgamating, the Geological Institute (MÁFI) has the broader topical profile, although it does not have the acumen or the flexibility of the Eötvös Lóránd Geophysical Institute (ELGI) in meeting today's issues.

Both of these institutes are still subservient to a Central Office of Geology, a Soviet-style supervisory organization that has roles in issuing permits for (State) industry exploration. "guiding" the sciences, and allocating the budget to the institutes. An anachronism in today's world, it never has had the scientific wherewithal to guide research, although, at one time, it was a politically powerful, independent organization because of its role in planning exploration. Its past indicates a strong preference for geologists, which caused the ELGI to seek increasingly more outside work, including customers for manufactured instruments.

\section{Steps of restructuring}

The first step recommended for restructuring was to dismantle the Central Office of Geology and hand its regulatory powers to the regulatory authority on mining according to the new mining law. This would restore the independence of the geological and geophysical institutes for defining their scientific goals. The second step was to bring the disciplines of the geosciences together and to expand the scope of activities in order to meet Hungary's current needs for geoscience information.

At one time, it seemed reasonable to replace the Central Office by an umbrella organization, provisionally called the Hungarian Geological Service, that would gather together the scattered institutes (geology, geophysics, engineering geology, geochemistry, geodynamics, seismology, hydrogeology, environmental geology, and perhaps even topographic mapping). Reluctance of various kinds (to share power, to share resources, and to share turf) eventually halted this effort. in no small part because these institutes were housed under different authorities.

Still, three institutes, the MÁFI, ELGI, and KBFI, were important to merge. Why? One reason is that the emphasis in Hungarian geology should have been shifted to basin analysis long ago because 80 percent of the country is made up of sedimentary fill in basins that have depths to basement commonly exceeding $6 \mathrm{~km}$. No thorough study exists of these basins (collectively, the Pannonian basin system) because, for instance, data from seismic-reflection profiles of one institute seldom met the geological core data of the other. The second reason is that practical solutions to waste disposal, siting of facilities, improving transportation infrastructure, and evaluating geohazards all need expertise from engineering geology. Third, and most importantly, the Government's budget cannot afford duplication. Therefore, the argument is uncontestable that a single agency is needed to fill the State's requirements for geological information and analyses.

The restructuring was conceived by the use of the following principles:

(1) The Government needs cohesive research results and products at regional scales (not commercial scales) and at a reasonable cost.

(2) Governmental geoscience activities should support the Government's policy preparation and decision making, including in energy and mineral development, environmental protection, infrastructure improvement, and natural resources management.
(3) Governmental geoscience activities should not duplicate or be in competition with the private sector.

(4) The public needs comprehensible and timely information.

(5) The activities should support the identification and resolution of long-range problems.

(6) The research and resulting information should meet internationally accepted standards.

According to these principles, the plan that was proposed consisted of the following steps:

(1) Close the Central Office of Geology and transfer its regulatory powers to the new Mining Office, which would result in commensurate cost savings (so stated in the draft mining law).

(2) Place the engineering geology group of the KBFI in the MÁFI.

(3) Privatize the activities of the ELGI that are not essential to governmental programs, and let the institute carry its name with it.

(4) Transfer the activities of the ELGI that serve the public to the MÁFI. (Steps 3 and 4 would be carried out with a declining amount of State budgetary support going to ELGI over a transitional time period of up to 2 years.)

(5) The new geological survey, consisting of elements of the MÁFI, ELGI, and KBFI, would serve not only as the singular governmental geoscience agency but also as the repository for all geologic data, including data from companies involved in mineral and energy exploration and production, civil engineering works, and the geological aspects of environmental studies. In regard to minerals, the survey would take a leading role in resource assessment and a major role in environmental impact analysis.

(6) This geological survey would have a line budget authorized by Parliament, and its Director would report to the Minister of Industry and Trade. The programs of the survey would be reviewed annually by an advisory committee for scientific aims and accomplishments.

(7) The above plan would forego establishing the "umbrella" geological service. meant to coordinate the institutes much as the Central Office of Geology did, although without the regulatory responsibilities of the Central Office.

\section{Patience, help, and support}

Accomplishing all of this requires patience, help, and support. Patience means that a transition period of $1-2$ years is necessary for moving and merging functions, during which a declining government budget must support the staff and facilities of the institutes and must allow eligible staff to retire gracefully. This may be called the "soft landing approach." A serious aspect of this process is beginning to be recognized, namely that, even after reform, it will be difficult to keep the geosciences in the political and budgetary forefront because they are viewed as less critical than, say, health, the environment, water resources, and other science issues long neglected. This represents an additional incentive to expand the responsibility of the geosciences from areas of classic disciplines to more practical, problem-solving ones.

The help needed is clearly in education and training, not only for benefiting government scientists but also for expanding and improving university curriculums in order to provide the next generation with a broader spectrum and more practical background. Shortcomings can be rectified now, especially among the younger, more eager scientists, by new courses taught, exchanges organized, and on-the-job training arranged inside and outside of Hungary. Such forms of education should aim to introduce advanced methods and technology, and the geoscience community is particularly receptive 
to such opportunities. The science and engineering staffs of commercial firms also would benefit from these efforts, and they need to become updated, if only to keep up with the influx of competing firms and their capabilities.

Support has to be built for the geosciences within, as well as outside, Hungary. In the former case, this places the onus first on the practitioners of the geosciences. The practitioners must develop projects and products that serve the common good at the broadest scales. No longer can they be an arm of industry. No longer should they concentrate on individual projects, and instead, they must adopt the team approach. Classic science is beneficial if it is practical and understandable, not esoteric. Hence, their new roles must include, in fact concentrate on, serving the needs of municipalities, individuals, and other agencies. The private sector can be served too, as long as work is done openly and the results are made public. The geoscientists must flag problems before they are recognized as problems, and their capabilities in solving them must be advertised widely. These steps will bring them recognition and acceptance and also will bring them closer to the Western geological surveys and associations. The Western surveys recognized long ago that their support is derived from the public needs that define and drive their budgets, but if these needs are served well, this support also allows them to do basic scientific research.

Geoscience is a global science, which is attested to well by a multitude of international programs. Hungarian geoscientists need to be involved in such programs at an increasing level in order to see other places, hear other ideas, and practice other approaches. Geoscience is an applied, interpretive, subjective discipline that uses analogies, models, comparisons, and much repeated testing, and it relies strongly on results produced by other scientific disciplines. It cannot be practiced well while confined to an area of $93,000 \mathrm{~km}^{2}$.

\section{Epilogue}

$N_{\text {ot long after this article was written, those upset with the concept }}$ proposed herewith - and accepted at the ministerial level-declared it too radical. Arguing for less sweeping and more cosmetic changes while calling this reform (in essence, changing name plates on the door), they called for a reexamination of the plans. Another committee, reviewing the issue with political speed, recently proposed a new concept that has been accepted at the ministerial level.

This new approach avoids the need to make unsavory decisions by passing that responsibility on to a board. The board shall supervise a public foundation called the Hungarian Geological Foundation. The Geological and the Geophysical Institutes will belong to this foundation, which will include their physical and financial assets. The board will be empowered not only to define the programs and budgets of the institutes but also to manage their combined assets, sell them or buy others, and make investments, as well as allocate financial resources for purposes outside the foundation's operative needs. The State will not guarantee the foundations' and, thus, the institutes' operating budget; it may contribute a part, but the rest will have to be obtained from other sources, mostly consulting work on behalf of other organizations and the private sector. The board shall not be accountable to the State, programmatically or fiscally, for more than the State's contribution to its budget.

This plan is replete with significant problems, ranging from misunderstandings to prospects of collusion. Granted, it was devised by people who think that capitalism is unregulated. The serious new issues raised by this plan are as follows:

- It leaves unresolved the integration of the geoscience disciplines and, instead, simply passes that responsibility to an undefined organizational entity that has no deadline.
- The programmatic and financial line authorities of the institutes are expropriated and conveyed to the multimember board, and the members' allegiance will reflect their political appointments.

- It transfers ownership of the Government's assets to an entity that is neither wholly supervisable by nor accountable to the Government, and it allows this entity a free hand in the management of these assets.

- While expecting reliable and unbiased public-service work and information, the plan allows the foundation to mix income sources from the Government with those from the private sector and thus develops a means for serious conflicts of interest such as, for example, in the awarding of mineral and oil and gas concessions.

- The foundation is allowed to make a profit because the definitions and legal basis for nonprofit operations do not exist.

- The plan gives no guidance as to what the role of governmental geoscience will be in Hungary or as to what is expected to be produced and according to what schedule.

- At an additional loss of time, the plan leaves unresolved the need to modernize facilities, provide training, control costs, and prepare long-range plans.

- From year to year, it produces an uncertain budgetary outlook because it allows the Government to choose what projects to finance, and it may disassociate itself from funding commitments altogether.

- As yet, no legal basis exists for establishing public foundations in Hungary.

No other geological survey operates in this mode in the Western World. We can only hope that such a geological survey will not operate in this mode in Hungary.

\section{Acknowledgments}

The conceptual parts of the reorganization were developed with the help of several people. Among those who merit special mention are Drs. István Bérczi, Gábor Gaál, and Peter Esztó of Hungary, James Devine of the U.S. Geological Survey, Dr. Peter Allen of the British Geological Survey, and Jan Olaf Carlsson of the Swedish Geological Institute. My thanks to all of them for their patience, perseverance, and sensible advice. $\square$

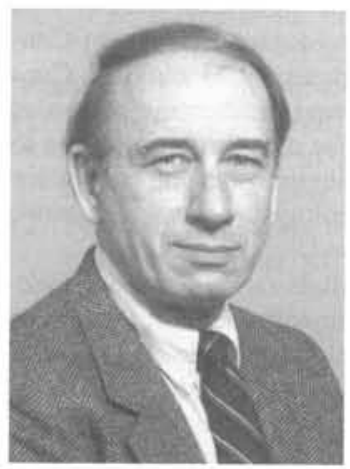

Dr. Paul G. Teleki, educated as a geologist, has been assisting the Government of the Republic of Hungary in restructuring the energy sector. On leave from the U.S. Geological Survey where he worked for 15 years, he took the position of Senior Advisor to the Hungarian Government in 1990. His assignments in Hungary have included developing legislation and the regulatory regime for oil and gas, hard minerals, and electrical energy and gas distribution, as well as advising on the restructuring of the oil and gas and electricity sector. In a related field, he has provided advice on the future role and functions of the Government's geoscience institutions. He was appointed Chairman of the Board of the Hungarian Oil and Gas Company, and he serves as Chairman of both the Hungarian Geological Sciences Foundation and the Hungarian National Committee to the World Petroleum Congresses. 